\title{
Heterotopic pregnancy: a case series
}

\section{Mounir Moukit*, Mohammed Rahmoune, Ismail Allilou, Bouchra Elmoubakkir, Omar Laghzaoui}

Department of Obstetrics and Gynaecology, Moulay Ismail Military Hospital, Morocco

Received: 30 November 2021

Revised: 09 January 2022

Accepted: 11 January 2022

\section{*Correspondence:}

Dr. Mounir Moukit,

E-mail: mounirmoukit@yahoo.com

Copyright: (c) the author(s), publisher and licensee Medip Academy. This is an open-access article distributed under the terms of the Creative Commons Attribution Non-Commercial License, which permits unrestricted non-commercial use, distribution, and reproduction in any medium, provided the original work is properly cited.

\begin{abstract}
Heterotopic pregnancy once considered a rare phenomenon is now thought to be more common as the overall incidence of ectopic pregnancy continues to increase. We report a series of six cases of heterotopic pregnancies seen in our department over a period of seven years. Two of these occurred after assisted reproductive techniques; while the other cases were spontaneous heterotopic pregnancies. The clinical presentation of these cases was varied with late diagnosis occurring in two cases. Preservation of the intrauterine pregnancy was obtained in four cases. Unfortunately, the other cases were aborted spontaneously on the postoperative period. Only with an early diagnosis and adequate management the intrauterine pregnancies will reach viability, with a great chance of a favorable obstetric outcome.
\end{abstract}

Keywords: Heterotopic pregnancy, Ultrasonography, Tocolysis, Surgery

\section{INTRODUCTION}

Heterotopic pregnancy (HP) is a rare form of twin pregnancy defined as the coexistence of intrauterine (IUP) and ectopic pregnancy (EP). Very few cases have been reported till date, especially case report. The incidence is increasing mainly due to increase in the development of medical procreation techniques. ${ }^{1}$ Significant morbidity and occasional mortality have been reported as a result of a delay in diagnosis. In this article, we report a case series of six patients managed in our department during a period of seven years (2014 to 2020) and we discuss the best practices for the diagnosis and treatment of this rare entity.

\section{CASE SERIES}

\section{Case 1}

A 25-year-old woman was a case of primary infertility for two years and ultrasound findings of polycystic ovary syndrome. She received ovulation induction by Clomiphene Citrate (CC) $100 \mathrm{mg} /$ day starting on day 2 of the cycle and continued with recombinant FSH on day 7. Transvaginal ultrasound on day 12 showed 2 good size follicles in the right ovary. She was given human chorionic gonadotropin (HCG) on day 12 and was advised for natural intercourse on day 13. Her next presentation was at 6 weeks of amenorrhea with lower abdominal pain. On physical examination, mild tenderness was found on deep palpation of the right lower abdominal quadrant. Transvaginal ultrasound scan revealed intrauterine gestational sac with fetal pole and visible cardiac activity. A small amount of free fluid was seen in the pouch of Douglas. Given her history of fertility treatment and her physical examination findings, adnexal areas were evaluated with particular detail. A second gestational sac with fetal pole and cardiac activity, adjacent to the right ovary, was visualized, suggestive of heterotopic pregnancy (Figure 1). An urgent mini-laparotomy was performed; there was a preruptured ectopic pregnancy in the ampullary region of the right fallopian tube. Salpingectomy was performed. Pathological examination confirmed the ectopic pregnancy. Per operatively, intravenous Nicardipine was prescribed for prevention of 
uterine contractions. The IUP was followed up till 41 weeks and she was induced (one dose of Misoprostol) with vaginal delivery of a healthy baby boy.

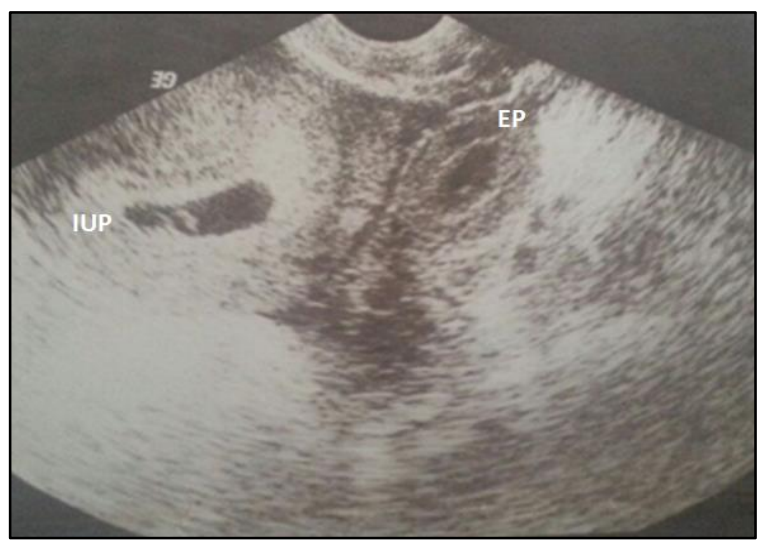

Figure 1: Simultaneous intrauterine and ectopic pregnancy.

\section{Case 2}

A 21-year-old woman, with a history of right ectopic pregnancy which was treated with Methotrexate two years before presented in our department for acute abdominal pain with amenorrhea for two months. Urine pregnancy test, made 10 days before, confirmed her pregnancy. On examination, the patient had a blood pressure of 90/60 $\mathrm{mmHg}$, pulse of 110 beats per minute, and there was a generalized abdominal distention with tenderness. Transvaginal ultrasonography showed a middle amount of free fluid in the peritoneal cavity, an intrauterine gestational sac without fetal pole, and a right heterogeneous mass, measuring $25 \mathrm{~mm}$. Her hemoglobin was $8 \mathrm{~g} / \mathrm{dl}$.

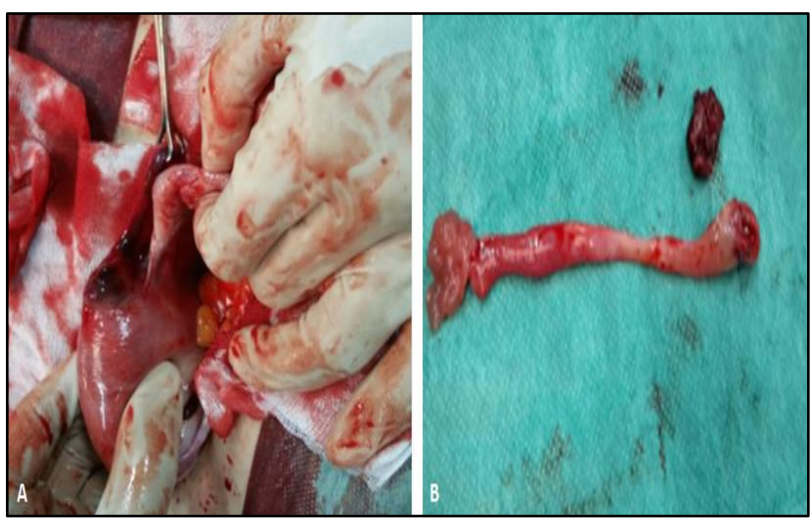

Figure 2: (A) Peroperative view revealing a ruptured right cornual pregnancy and $(B)$ macroscopic view of the resected specimen.

She was planned for urgent mini-laparotomy with the differential diagnosis of intrauterine pregnancy with either ruptured corpus luteum or hemorrhagic ovarian cyst, thinking least of heterotopic pregnancy. Laparotomy revealed approximately $500 \mathrm{~mL}$ of hemoperitoneum and a ruptured right cornual pregnancy; enucleation of the cornual pregnancy was performed with right salpingectomy (Figure 2). Unfortunately, she aborted spontaneously on the second postoperative day.

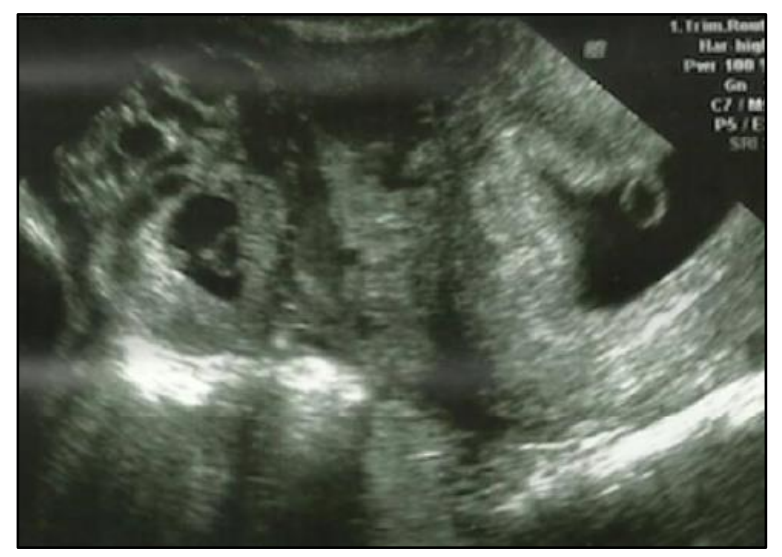

Figure 3: Transvaginal ultrasound showing simultaneous intrauterine and ectopic pregnancy at 6 weeks of gestation.

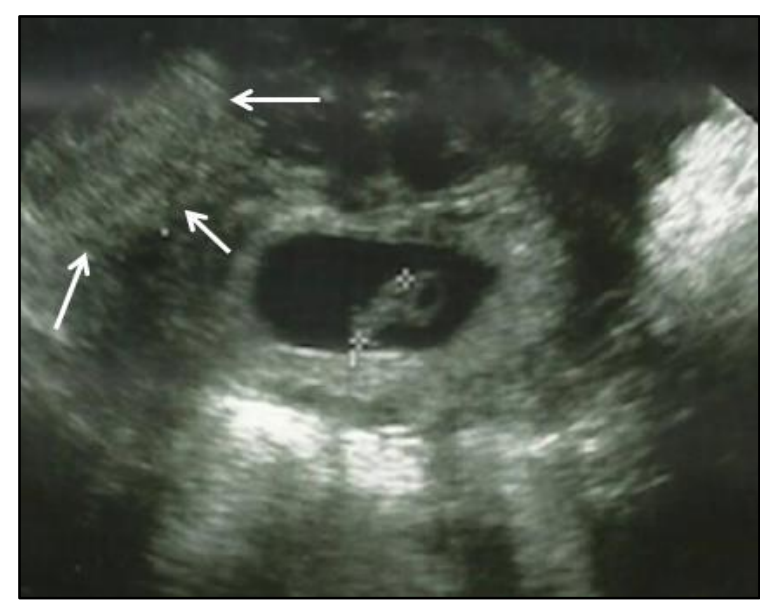

Figure 4: The intrauterine pregnancy with a right heterogeneous pelvic structure (white arrows).

\section{Case 3}

A 32-year-old woman, gravida 2, parity 1, presented to the gynecological emergencies with the chief complaint of lower abdominal pain appeared 48 hours before. At this time, the patient was pregnant at 6 th week of gestation. She conceived spontaneously and she had no history of pelvic inflammatory disease (PID). Physical examination showed mild tenderness at the right lower abdomen; pouch of Douglas was painful on palpation with no bleeding from the uterine cervix. Transvaginal ultrasonography objectified simultaneous intra and extrauterine gestational sacs according to 6 weeks of gestation with current cardiac activity of both embryos (Figure 3 ). Patient was consented for an operative laparotomy few hours later. A total of 200 $\mathrm{mL}$ of hemoperitoneum was aspirated. The uterus was enlarged according to the gestational age. 
Table 1: Cases characteristics.

\begin{tabular}{|c|c|c|c|c|c|c|}
\hline & Case 1 & Case 2 & Case 3 & Case 4 & Case 5 & Case 6 \\
\hline Age (years) & 25 & 21 & 32 & 40 & 28 & 24 \\
\hline Gravida/parity & $1 / 0$ & $2 / 0$ & $2 / 1$ & $1 / 0$ & $2 / 1$ & $1 / 0$ \\
\hline $\begin{array}{l}\text { Gestational age } \\
\text { (weeks) }\end{array}$ & 6 & 8 & 6 & 6 & 7 & 8 \\
\hline Risk factors & $\begin{array}{l}\text { Ovulation } \\
\text { induction }\end{array}$ & $\begin{array}{l}\text { History of } \\
\text { right EP }\end{array}$ & - & PID and IVF & - & - \\
\hline $\begin{array}{l}\text { Clinical } \\
\text { presentation }\end{array}$ & Pelvic pain & $\begin{array}{l}\text { Abdominal } \\
\text { pain }\end{array}$ & $\begin{array}{l}\text { Pelvic } \\
\text { pain }\end{array}$ & Pelvic pain & $\begin{array}{l}\text { Pelvic pain and } \\
\text { vaginal } \\
\text { bleeding }\end{array}$ & $\begin{array}{l}\text { Abdominal } \\
\text { pain }\end{array}$ \\
\hline Ultrasonography & IUP and EP & $\begin{array}{l}\text { IUP and right } \\
\text { mass }\end{array}$ & $\begin{array}{l}\text { IUP } \\
\text { and EP }\end{array}$ & $\begin{array}{l}\text { IUP and right } \\
\text { mass }\end{array}$ & $\begin{array}{l}\text { IUP and left } \\
\text { mass }\end{array}$ & $\begin{array}{l}\text { IUP and right } \\
\text { mass }\end{array}$ \\
\hline $\begin{array}{l}\text { Implantation } \\
\text { site of EP }\end{array}$ & Right tube & Right cornua & $\begin{array}{l}\text { Right } \\
\text { tube }\end{array}$ & Right tube & Left ovary & Right tube \\
\hline Management & Salpingectomy & Salpingectomy & $\begin{array}{l}\text { Salping } \\
\text { ectomy }\end{array}$ & Salpingectomy & $\begin{array}{l}\text { Pregnancy } \\
\text { resection }\end{array}$ & Salpingectomy \\
\hline $\begin{array}{l}\text { Prophylactic } \\
\text { tocolysis }\end{array}$ & Nicardipine & - & $\begin{array}{l}\text { Nicardi } \\
\text { pine }\end{array}$ & - & - & - \\
\hline IUP prognosis & Healthy baby & Abortion & $\begin{array}{l}\text { Healthy } \\
\text { baby }\end{array}$ & Healthy baby & $\begin{array}{l}\text { In the } 3^{\text {rd }} \\
\text { trimester }\end{array}$ & Abortion \\
\hline
\end{tabular}

PID: pelvic inflammatory disease IVF: in vitro fertilization

The left annex and right ovary were normal with a ruptured ectopic pregnancy in the ampullary region of the right fallopian tube. A right salpingectomy was performed and the material was sent for histological examination confirming chorionic villi. Nicardipine (Loxen $®$ ) was used for tocolysis. The IUP proceeded well, and the labor was performed at term with a healthy baby.

\section{Case 4}

A 40-year-old nulliparous woman was referred to our department for acute pelvic pain. Her medical history revealed a treated pelvic inflammatory disease. Hysterosalpingography had shown bilateral fallopian tubes obstruction and she underwent an in vitro fertilization (IVF) cycle at a local clinic. When she came to the emergency room, it was 23 days after SET. Transvaginal ultrasonographic examination revealed an intrauterine pregnancy corresponding to 6 weeks gestation with a right heterogeneous structure measuring $2.3 \mathrm{~cm}$ associated with minimal fluid collection in the pelvis (Figure 4).

Given his history, the primary clinical diagnosis was heterotopic pregnancy. Peroperatively, the right fallopian tube was dilated and appeared to have hemorrhagic and trophoblastic tissues, suggestive of an ectopic pregnancy. Laparoscopic right salpingectomy was performed under prophylactic tocolysis.

The pathologic report confirmed the ectopic pregnancy. Her intrauterine pregnancy was uneventful postoperatively and a healthy girl weighing $3000 \mathrm{~g}$ was born vaginally at 38 weeks of gestation.

\section{Case 5}

A 28-year-old woman, gravida 2, parity 1, was admitted in our department for lower abdominal pain and vaginal bleeding. At this time, the patient was pregnant at 7 th week of gestation. She conceived spontaneously without previous fertility treatment. Gynecological examination revealed a tender mass, measuring approximately $7 \mathrm{~cm}$ at the left annex with painful Pouch of Douglas on palpation. Transvaginal sonography showed the viable intrauterine pregnancy; in addition, there was a left ovarian heterogeneous and vascular mass, which had total size of $5 \mathrm{~cm}$. The patient was consented for an operative laparotomy few hours later. A total of $300 \mathrm{ml}$ of hemoperitoneum was aspirated. The right adnexa and left fallopian tube were normal. However, the left ovary presented a circular formation measuring $5 \mathrm{~cm}$ and containing trophoblastic tissue. Complete removal of the supposed ovarian pregnancy was performed and the histologic examination confirmed chorionic villi suggestive of an ovarian HP. The postoperative course was uneventful. Actually, the viable intrauterine pregnancy is at the 3rd trimester and followed in our Department.

\section{Case 6}

A 24-year-old primigravida, presented with 8 weeks of amenorrhea and severe abdominal pain appeared 4 hours before. The pain was diffuse all over the abdomen. On examination she was pale, blood pressure was $80 / 30 \mathrm{~mm}$ $\mathrm{Hg}$ and pulse 115 beats/minute. Abdomen was tender over the suprapubic region with rigidity. Gynecological examination revealed closed cervix without vaginal bleeding and fullness in both right and left fornixes. Abdominal ultrasonography showed free fluid in the 
abdominopelvic cavity with intrauterine pregnancy and visible cardiac activity in addition of a right adnexal mass measuring $30 \mathrm{~mm}$. She was planned for an exploratory laparotomy with the differential diagnosis of IUP with either ruptured corpus luteum cyst or hemorrhagic ovarian cyst, thinking least of HP. During laparotomy, an amount of 2 litres of hemoperitoneum was aspirated. Uterus was enlarged according to gestational age and there was a ruptured right ampullary pregnancy. The left tube and both ovaries were normal. Right salpingectomy was done and she received 4 units of blood per and postoperatively raising the postoperative hemoglobin to $10 \mathrm{~g} / \mathrm{dl}$. Her postoperative period was uneventful. Pelvic sonography realized on the second postoperative day showed a single live intrauterine pregnancy with normal cardiac activity. The pathologic report of the specimen confirmed the EP. She was discharged from the hospital on the 3th postoperative day. Unfortunately, she aborted spontaneously on the 5 th postoperative day.

\section{DISCUSSION}

Heterotopic pregnancy is one of the rarest types of multiple gestations. Its incidence is known to be one in 8,000 to 30,000 in spontaneous conceptions. The rates are 30-60 times higher after assisted reproductive techniques. ${ }^{1,2}$ Its first description was done during an autopsy by Duverney in 1708, which was followed by its identification in ovulation induction, in vitro fertilization-embryo transfer, as well as during gamete fallopian transfer. ${ }^{3}$ It mostly happens with known risk factors notably tubal or pelvic surgery, assisted reproductive techniques, ovulation induction, history of pelvic inflammatory disease, previous ectopic pregnancy. The risk factors we have found in our cases were ovulation induction in case one, previous history of ectopic pregnancy in case two, history of pelvic inflammatory disease and IVF in case four. However, the other cases were a challenging one as they did not have any of the known risk factors in addition of endometriosis or tubal anomalies (according to peroperative exploration). HP can occur in different forms: IUP and tubal, abdominal, cornual, cervical, cesarean scar, or ovarian pregnancy. Fallopian tube is the most frequent reported site (72\%), as was in our case series. ${ }^{4}$ Kitade et al have described a rare case of HP associating simultaneous tubal and splenic pregnancy following assisted reproductive technique. ${ }^{5}$ Preoperative diagnosis of HP remains a major challenge and requires a high index of suspicion because of the detection of an intrauterine implanted embryo can mask the need to scan the adnexa in asymptomatic patient. Around $50 \%$ of cases are asymptomatic and diagnosed very late with significant morbidity and sometimes mortality, as was in cases two and six. When symptomatic, the clinical features are abdominal pain, vaginal bleeding, hypovolemic shock and adnexal mass. ${ }^{6}$ Abdominal ultrasonography, especially transvaginal, is crucial in the diagnosis. Simultaneous visualization of intrauterine and $\mathrm{EP}$ is the gold standard for the diagnosis of $\mathrm{HP} .^{7}$ In a review of the literature (112 cases of HP), 46 were diagnosed by ultrasound while 66 were diagnosed peroperatively. ${ }^{8}$ According to reviews, in 77 to $85 \%$ of cases in whom diagnosis was via ultrasonography, diagnosis was made between five and eight weeks of gestation, as was in our case series. ${ }^{9}$ In some centers, magnetic resonance imaging (MRI) is done to rule out HT pregnancy. ${ }^{10}$ Plasmatic beta human chorionic gonadotropin (beta-hCG) level is often difficult to interpret during HP, because the IUP causes the beta-hCG level to rise appropriately. The gold standard treatment for HP is surgery (laparoscopy or laparotomy). Laparoscopic surgery is preferable if the patient is hemodynamically stable; however, emergency laparotomy is the only choice if the hemodynamic status is compromised. The main aim of this surgery should be the preservation of the IUP with minimal manipulation of the uterus. The choice between salpingotomy and salpingectomy may be difficult. A review demonstrated no difference in survival rates of IUP after conservative or radical surgery for tubal ectopic pregnancy. ${ }^{11}$ In our case series, lack of laparoscopic equipment in the operating room, mini-laparotomy was performed in all cases with salpingectomy for rapid management of active bleeding. IUP outcome after surgery depends on many factors: gestational age at diagnosis, operative time, quality of anesthesia and surgery (minimal uterine manipulation). In case two, we suggest that the absence of peroperative tocolysis was a factor of IUP abortion on the second postoperative day. We suggest also that low quality and longtime of surgery (realized by a resident) was a factor of postoperative abortion in case six. In Table 1, we summarized clinic-pathological features of our patients. Medical treatment can be used to manage patients who are clinically stable and where a HP is diagnosed early. Scheiber et al have reported a successful management of six cases of HP using potassium chloride (KCL) injection into the tubal EP. ${ }^{12}$ Moreover, since the risks of continued growth and rupture still exist with such treatment, repeated ultrasonography and close monitoring of clinical symptoms are mandatory. A publication of HP treated with KCL injection noted that $55 \%$ of cases failed this therapy and required surgery. ${ }^{13}$ Selective embryo aspiration under ultrasound guidance has also been described. However, it demands expertise to do the procedure, and there is a high incidence of treatment failure, tubal rupture, delayed bleeding, and hematoma formation. ${ }^{14}$

\section{CONCLUSION}

Heterotopic pregnancy must always be considered in patients presenting with pelvic pain even in a confirmed intrauterine pregnancy, particularly if ovulation induction or assisted reproductive techniques have done. Surgical approach with minimal uterine manipulation and prophylactic tocolysis should be preferred to preserve the intrauterine ongoing pregnancy.

\section{Funding: No funding sources Conflict of interest: None declared Ethical approval: Not required}




\section{REFERENCES}

1. Reece EA, Petrie RH, Sirmans MF, Finster M, Todd WD. Combined intrauterine and extrauterine gestations: a review. Am J Obstet Gynecol. 1983;146:323-30.

2. Maruotti GM, Sarno L, Morlando M, Sirico A, Martinelli P, Russo T. Heterotopic pregnancy: it is really a rare event? The importance to exclude it not only after in vitro fertil-ization but also in case of spontaneous conception. Fertil Steril. 2010;94:e49.

3. Alptekin H, Dal Y. Heterotopic pregnancy following IVF-ET: successful treatment with salpingostomy under spinal anesthesia and continuation of intrauterine twin pregnancy. Arch Gynecol Obstet. 2014;289:911-14.

4. Barrenetxea G, Barinaga-Rementeria L, Lopez DE, Agirregoikoa JA, Mandiola M, Carbonero K. Heterotopic pregnancy: two cases and a comparative review. Fertil Steril. 2007;87(417):e9-15.

5. Kitade M, Takeuchi H, Kikuchi I, Shimanuki H, Kumakiri J, Kinoshita K. A case of simultaneous tubal-spenic pregnancy after assisted reproductive technology. Fertil Steril. 2005;83(4):1042.

6. Kouach J, Moukit M, Ait El Fadel F, El Fazazi H, Guelzim K, El Hassani ME, et al. Heterotopic Pregnancy following Ovulation Induction: A Case Report. Austin Gynecol Case Rep. 2017;2(1):1011.

7. Jaouad K, Mounir M, Rachid A, El Mehdi EM, Abdellah B, Driss MR, et al. Heterotopic pregnancy: A report of three cases and a brief comparative review. Saudi J Health Sci. 2017;6:126-9.
8. Tandon R, Goel P, Saha PK, Devi L. Spontaneous heterotopic pregnancy with tubal rupture: a case report and review of the literature. J Med Case Reports. 2009;3:8153.

9. Mehrabian F, Robati BK. Heterotopic abdominal pregnancy following ovulation induction with Clomiphene citrate. Iran J Reprod Med. 2010;8:51-4.

10. Luo X, Lim CE, Huang C, Wu J, Wong WS, Cheng NC. Heterotopic pregnancy following in vitro fertilization and embryo transfer: 12 cases report. Arch Gynecol Obstet. 2009;280:325-29.

11. Aust T, O’Neill A, Cario G. Purse-string suture technique to enable laparoscopic management of the interstitial gestation of a heterotopic pregnancy. Fertil Steril. 2011;95:261-3.

12. Scheiber MD, Cedars MI. Successful non-surgical management of a heterotopic an abdominal pregnancy following embryo transfer with cryopreserved-thawed embryos. Hum Reprod. 1999;14:1375-7.

13. Goldstein JS, Ratts VS, Philpott T, Dahan MH. Risk of surgery after use of potassium chloride for treatment of tubal heterotopic pregnancy. Obstet Gynecol. 2006; 107:506-8.

14. Nabi U, Yousaf A, Ghaffar F, Sajid S, Ahmed MM. Heterotopic Pregnancy - A Diagnostic Challenge. Six Case Reports and Literature Review. Cureus. 2004;11(11):e6080.

Cite this article as: Moukit M, Rahmoune M, Allilou I, Elmoubakkir B, Laghzaoui O. Heterotopic pregnancy: a case series. Int J Reprod Contracept Obstet Gynecol 2022;11:590-4. 